\title{
Implicit Content and the Argument from Binding
}

\author{
Paul Elbourne \\ Queen Mary, University of London
}

\section{Introduction}

In some utterances, some material does not seem to be explicitly expressed in words, but nevertheless seems to be part of the literal content of the utterance rather than an implicature. I will call material of this kind implicit content. The following are some relevant examples from the literature.

(1) Everyone was sick.

(2) I haven't eaten.

(3) It's raining.

In the case of (1), we are supposed to have asked Stephen Neale how his dinner party went last night (Neale 1990: 94-95) and received this as the reply. Obviously, we do not take Neale to be saying that everyone in the world was sick; we interpret him as saying that everyone who attended his dinner party was sick. How, then, do we come to incorporate the property of attending Neale's dinner party into the proposition expressed, when it does not seem to be the denotation of any overt lexical items in the utterance? In uttering (2), I might be asserting that I have not eaten dinner today (Bach 1994: 135-136), even though I do not use any audible words meaning 'dinner' or 'today'. (I might thereby intend to create an implicature to the effect that we should go to a restaurant.) And in saying (3), I might be claiming that it is raining at 11.59pm on Halloween 2008 in Arkham, Massachusetts, even though I do not appear to mention any place (Perry 1986, Stanley 2000, Recanati 2002, 2004, 2007, Martí 2006, Neale 2007).

I will be concentrating on two questions about implicit content. The first is the question of the level of representation at which implicit content first makes its presence felt. Are there unpronounced items in the syntax of the sentence uttered whose semantic value is implicit content? If so, what are their syntactic properties? Or does implicit content leave no trace, as it were, in the syntax but appear only in conceptual representations or the language of thought?

\footnotetext{
Versions of this article have been given as talks at the University of Chicago Linguistics Department colloquium series, the second Oxford-Paris Workshop in the Philosophy of Language (Oxford University), and SALT 18 (University of Massachusetts, Amherst). I am grateful to the audiences on those occasions for their comments, especially to Nicholas Asher, Anastasia Giannakidou, John Hawthorne, Chris Kennedy, Ofra Magidor, Jason Merchant, Jerry Sadock, Jason Stanley and Timothy Williamson. Correspondence with Stephen Neale and Jason Stanley has been very illuminating. All errors are mine.
} 
The second question might be called the problem of the logical form of implicit content. How does it combine with the content provided by the overt constituents in the syntax? I will distinguish two approaches to this latter problem: the global approach and the local approach. The global approach says that the content derived from the overt constituents in the syntax is asserted to be true only of a restricted spatiotemporal part of the world. ${ }^{1}$ The local approach says that implicit content can be interwoven with the content provided by overt constituents in the syntax: it could be the value of unpronounced variables in the syntax, as just mentioned, or it could be added to the language of thought constituents that indicate (or are) the semantic values of items in the syntax.

The global approach is subject to what are widely considered to be insuperable objections (Westerståhl 1985, Soames 1986), and I will not consider it in detail in this paper. I will, however, distinguish four variants of the local approach (Section 2); these variants differ, among other things, on whether they claim that the syntax is crucially relevant, as described in the first question. Stanley (2000, 2002a) and Stanley and Szabó (2000) have put forward an argument known as the argument from binding that they claim supports their variant of the local approach over others; in Section 3, I try to show that the argument from binding does not do the work that Stanley and Szabó want it to do. However, I then go on, in Section 4, to present a variant of the argument from binding that constitutes evidence against Stanley and Szabó's position and against some other variants of the local approach. Section 5 concludes.

\section{The Local Approach}

Four versions of the local approach are prominent in the literature. I will examine them in turn.

\subsection{The Syntactic Relation Variable Approach}

The first version is what we might call the syntactic relation variable approach. According to this theory, there are unpronounced variables in the syntactic structure of the sentence. The content of these variables is established by whatever mechanism fixes the content of overt indexicals. Their positioning is in principle subject to syntactic constraints. Theories of this kind have been advocated by von Fintel (1994), Stanley (2000, 2002a,b), Stanley and Szabó (2000) and Martí (2003, 2006).

Here is an example of the syntactic relation variable approach. Suppose that determiners can come with an unpronounced pair of a relation variable and an individual variable (von Fintel 1994: 30-31). Determiners take this pair as their first argument and then take the overt nominal. In the case of (4), we would have a

\footnotetext{
${ }^{1}$ This is the same as what Neale (1990: 95) calls the implicit approach. However, I will not talk in terms of Neale's distinction between implicit and explicit approaches, since it does not accommodate some varieties of what I here call the local approach. See the extensive terminological remarks in Neale 2004, and in particular his footnote 126 (2004: 159).
} 
syntactic structure like that in (5).

(4) The table is covered with books.

(5) $\quad[[[$ the $[\mathrm{R}$ pro $]]$ table] [is covered with books $]]$

In this example, we might imagine that pro, the individual variable, has as its value a particular room, the one containing the table in question. Let $a$ be a name for this room. The relation variable $\mathrm{R}$ might be assigned a meaning equivalent to that of in. In the semantics, the denotation of the definite article would take two arguments and intersect them. On this occasion, they would be the property of being in $a$ and the property of being a table. So the definite description ends up meaning 'the table in $a^{\prime}$.

Of course we could have arrived at a meaning like 'in $a$ ' just with a property variable. Why do we need a combination of an individual variable and a relation variable? The following sentence is a good reason why (von Fintel 1994: 31). (6) seems to have the reading in (7). This means that we can use the apparatus we have introduced as shown in the simplified syntactic structure (8).

(6) Only one class was so bad that no student passed the exam.

(7) Only one class $x$ was so bad that no student in $x$ passed $x$ 's exam.

(8) [only one class] $\lambda_{2}$ [t $\mathrm{t}_{2}$ was so bad that no $\mathrm{R}_{1} \mathrm{pro}_{2}$ student passed the $\mathrm{R}_{3} \mathrm{pro}_{2}$ exam]

I follow Heim and Kratzer 1998 in positing a $\lambda$-operator in the syntax, below the subject. The individual variable pro $_{2}$ is bound by this operator, as is the trace $t_{2} ; R_{1}$ once again means 'in', and $\mathrm{R}_{3}$ will be assigned a value something like 'of', in the sense of 'belonging to' or 'associated with'. This will produce the attested meaning. Stanley and Szabó (2000) propose a variant of von Fintel's theory whereby the silent variables appear on nouns rather than on determiners. So (9) would have the syntactic structure in (10); (11) would have the simplified syntactic structure in (12).

(9) The table is covered with books.

(10) [[the [table $\left[\mathrm{R}_{1}\right.$ pro 2$\left.\left.]\right]\right]$ [is covered with books]]

(11) Only one class was so bad that no student passed the exam.

(12) [only one class] $\lambda_{2}$ [t $\mathrm{t}_{2}$ was so bad that no student $\mathrm{R}_{1}$ pro 2 passed the exam $\left.\mathrm{R}_{3} \mathrm{pro}_{2}\right]$

When two syntactic constituents denoting properties appear as sisters, as in the present examples, their semantic values will be intersected. Apart from the difference in placement of the variables, Stanley and Szabó's theory works like von Fintel's. 


\subsection{The Pragmatic Enrichment Approach}

The second version of the local approach to implicit content can be called the pragmatic enrichment approach (Sperber and Wilson 1986: 189). According to varieties of this theory, the output of the semantics is an object in a conceptual system or language of thought (Fodor 1975). Supplementation of this object occurs in the language of thought to obtain the mental object that corresponds to (or is) the literal content of the utterance. For example, suppose that John and Mary have guests, John enters the house noisily and Mary says (13) to him.

(13) Everyone is asleep!

From the conceptual representation in (14), John (or some aspect of John's inferential faculties) proceeds to (15). ${ }^{2}$

EVERYONE IS ASLEEP

EVERYONE WHO IS A GUEST OF MINE IS ASLEEP

The syntax, then, is not involved, in contrast to the syntactic relation variable approach. Theories along these lines have been advocated by Sperber and Wilson (1986), Carston (1988, 2002), Recanati (1993) and Bach (1994, 2005).

Importantly, these theories do not generally incorporate any syntactic restrictions on where in a language of thought object this supplementation can take place (using syntactic now to refer to the hypothesized syntactic qualities of the language of thought—see Fodor 1975): Sperber and Wilson, for example, say that this kind of enrichment "involves the application, not of special-purpose decoding rules, but of general-purpose inference rules, which apply to any conceptually represented information" (1986: 176); they suggest only a pragmatic principle (their principle of relevance) for arriving at appropriately disambiguated and enriched propositional representations (1986: 184). Theories of this kind, then, are potentially vulnerable in the following way: if a reading turns out to be unavailable for a given sentence, they cannot avail themselves of syntactic constraints to explain its absence, unlike the theories that belong to the syntactic relation variable approach; and they will face real difficulty if the reading in question can be argued to be pragmatically plausible. It is this vulnerability that I attempt to exploit in Section 4 of this paper.

\subsection{The Explicit Approach}

The third version of the local approach is the "explicit approach" of Stephen Neale (1990, 2004). Here is a description of it (Neale 2004: 121):

The basic idea is explicitly modal: the nominal is often shorthand for, elliptical for, an abbreviation of at least one richer nominal the speaker

\footnotetext{
${ }^{2}$ I follow the usual convention of representing language of thought strings as English sentences in capitals.
} 
could have used and could produce if asked to be more explicit. (Hence the name.) Consider the following dialogue:

A: The table is scratched.

B: Which table?

A: The table I bought this morning. (Or: The one I bought this morning.)

According to the explicit approach, this type of dialogue is suggestive of what is going on when we make felicitous uses of incomplete descriptions. $B$ is intended to interpret $A$ 's utterance of 'the table' as if it were an utterance of 'the table I bought this morning'. There need not be a unique description that $A$ can supply, but there had better be at least one-and one that $B$ could reasonably have been expected to construct at that - if the speech act is to be felicitous.

Neale (2004: 122, 167) is emphatic that the explicit approach does not involve syntactic deletion of the kind seen in discussions of VP-ellipsis and NP-deletion in syntactic theory. It is not the case, for example, that the relative clause I bought this morning is present in the syntax in A's first utterance above, but just not pronounced.

Is there any difference, then, between Neale's position and what I just referred to as the pragmatic enrichment approach? There is. According to the pragmatic enrichment approach, we act directly on language of thought representations without further reference to the syntax when we understand an utterance that involves implicit content. Neale (2004: 82-83) is content to assume a language of thought and to assume that understanding an utterance involves entertaining a particular language of thought representation. But according to Neale there is a limit on the kind of enrichment of language of thought strings that is permitted: we have to understand phrases involving implicit content as if they were phrases produced by adding words to the phrases actually uttered (Neale 2004: 122).

This difference between Neale's explicit approach and the pragmatic enrichment approach makes Neale's theory in a certain respect more constrained. Enrichment in Neale's theory can only yield meanings that could be obtained by syntactically building on the material present in the syntax. No such constraint is present in the pragmatic enrichment theory. As we will see, Neale will be in a position to claim an advantage for his theory because of this aspect of it.

\subsection{The Syntactic Situation Variable Approach}

The fourth and final version of the local approach that I will consider might be called the syntactic situation variable approach. Kuroda (1982), Recanati (1996, 2004) and Kratzer (2004) have proposed that implicit content is provided by each predicate being associated with a situation variable in the syntax, so that different predicates in one sentence can be evaluated with respect to different parts of the world (or even different parts of different possible worlds).

Detailed versions of the compositional semantics of systems like this have 
been provided by Percus (2000) and Büring (2004). ${ }^{3}$ Here is a brief sketch, based roughly on their ideas. A sentence like (16) would have an LF like (17).

(16) Every subject is asleep.

$$
\left.\left.\left.\Sigma_{8}\left[\left[\text { every [subject } \mathrm{s}_{8}\right]\right] \text { [is [asleep s8 }\right]\right]\right]
$$

By means of a syncategorematic rule, the operator $\Sigma_{8}$ is interpreted as a lambda operator binding coindexed variables in its scope. A predicate like subject or asleep will take a situation variable as its argument and return the characteristic function of the set of individuals with the relevant property in the situation in question. (Alternatively, depending on the details of the system being used, it might return an intensionalized version of that characteristic function.) So the semantic value of [asleep $s_{8}$ ] might be something like [ $\lambda x . x$ is asleep in $s_{8}$ ], where $s_{8}$ will end up being bound. (Note the difference between situation variables in the syntax, written in upright type, and situation variables in the metalanguage, written in italics.) The semantic value of the whole LF (17) will be something like (18).

$$
\lambda s_{8} . \text { every subject in } s_{8} \text { is asleep in } s_{8}
$$

Utterances of propositional LFs will typically express Austinian propositions, which are pairs of functions like (18) and topic situations that speakers are trying to say something about. If the topic situation in an Austinian proposition is a member of the set defined by the lambda-term, the speaker has spoken truly.

In this initial example, all situation variables are bound by the $\Sigma$ operator. But at least some of the situation variables in a sentence, according to the current theory, are capable of being referential. They can refer to particular spatiotemporal parts of the world. Take Soames's (1986) example (19).

(19) Everyone is asleep and is being monitored by a research assistant.

This would have a simplified LF something like the following:

$\Sigma_{8}\left[\right.$ [every [-one $\left.\left.\mathrm{s}_{1}\right]\right]$ [[is asleep $\left.\mathrm{s}_{8}\right]$ and [is being monitored $\mathrm{s}_{8}$ by a research assistant $\left.\left.\left.\mathrm{s}_{8}\right]\right]\right]$

The situation variable $s_{1}$ would refer to a (possibly doughnut-shaped) part of the world $s_{1}$ that contained the experimental subjects and no-one else, while the variables $s_{8}$ would be bound, as before, by the $\Sigma$ operator. The semantic value of this LF would be as follows:

(21) $\lambda s_{8}$. everyone in $s_{1}$ is asleep in $s_{8}$ and being monitored by a research assistant in $s_{8}$

\footnotetext{
${ }^{3}$ The system in Elbourne 2005, with its operator s $\mathrm{s}_{0}$ (Elbourne 2005: 103), would also deal successfully with the examples considered here.
} 
If this function is paired with a topic situation that includes the experimental subjects and the research assistant, the right results, it seems, will be obtained.

\section{The Argument from Binding}

Stanley (2000, 2002a,b) and Stanley and Szabó (2000) allege that the syntactic relation variable approach is superior to the pragmatic enrichment approach because of cases where there seems to be a bound variable in the implicit material. Examples are (22a) and (23a), which have the readings in (22b) and (23b) respectively.

a. In every room in John's house, every bottle is in the corner.

b. Every room $x$ in John's house is such that every bottle in $x$ is in the corner of $x$.

a. Every student answered every question.

b. Every student $x$ answered every question on $x$ 's exam.

Stanley (2002a: 153) gives the following summary of the force that these data are supposed to have:

One characteristic syntactic feature of pronouns is their capacity to be bound by variable-binding operators. By demonstrating the existence of bound readings of quantifier-domain variables, one provides evidence of behavior that is explicable on the assumption that there is an unpronounced pronominal element, and difficult to explain otherwise.

In itself, then, the argument from binding does not show that other theories, such as the pragmatic enrichment approach, cannot handle the data in question. But Stanley (2002a) attempts to show that the pragmatic enrichment approach, in particular, cannot deal with the data in question without encountering serious problems. I will now review these arguments.

Stanley (2002a) begins the relevant section of his paper by sketching a pragmatic process that could in principle allow speakers to communicate propositions with implicit content including bound variables, without corresponding bound variables occurring in the syntactic structure of the sentence uttered. Here is what he says (Stanley 2002a: 160):

Suppose that interpreters, when they hear a sentence whose semantic content in context is either less than fully propositional or expresses a proposition that the speaker clearly does not intend to communicate, quite automatically replace the uttered sentence by another one, one that contains additional words. This more complicated sentence, relative to that context, would semantically express the proposition the speaker intends to communicate, and the interpreter in fact grasps. But the recovery of this more developed sentence, although often fairly automatic and almost always unconscious (or tacit), is still a pragmatic process. 
Two remarks are worth making about the theory sketched in this passage: one, although Stanley does not say this, it is seemingly indistinguishable from Neale's (1990, 2004) explicit approach, since it talks about the proposition obtained by adding more words to the original sentence uttered; and two, it does not take account of the resources that the advocates of the pragmatic enrichment approach have at their disposal, since these latter can say that a bound variable is added at the relevant place in a language of thought string with no reference to the syntactic structure of the original sentence (Carston 2002: 198-200). We will want to distinguish carefully between points Stanley makes that affect only Neale's explicit approach and points he makes that are relevant for the pragmatic enrichment approach too.

Stanley's first criticism is relevant only to Neale's explicit approach. Stanley (2002a: 162) claims that on this theory it is mysterious why vacuous quantification causes ungrammaticality. Why, Stanley asks, should the following sentences be ungrammatical?

*Everyone who John ran, he likes.

*Everyone has had the privilege of having John greet.

After all, if there was a process that allowed an interpreter to replace the uttered sentence with a different one obtained by adding more lexical material, including bound variables, an interpreter should be able to hear (24) and (25) and replace them with the (26) and (27), respectively.

(26) Everyone who $_{1}$ John ran by $\mathrm{t}_{1}$, he likes.

(27) Everyone has had the privilege of having John greet her.

Why should the new sentence not alleviate the ungrammaticality of the original one, as well as providing it with a particular meaning?

To this criticism, I think we can very well answer "Why should it?" The kind of process postulated by Neale and criticized by Stanley is one whose purpose is to provide interpretations, not alleviations of ungrammaticality. Perhaps in judging the grammaticality of an utterance we judge what was uttered rather than our pragmatically triggered modification of it.

The next part of Stanley's (2002a) criticism of pragmatic enrichment theories is relevant both to Neale's explicit approach and the pragmatic enrichment theories themselves. Stanley (2002a: 164) points out that many ungrammatical sentences are nevertheless interpretable. He claims that, even if the theories in question do not predict (24) and (25) to be grammatical with the meanings of (26) and (27), they do nevertheless predict them to be interpretable with the meanings of (26) and (27). He maintains, however, that (24) and (25) are "well-nigh impossible to interpret" (Stanley 2002a: 164), which would be mysterious on the hypotheses under investigation.

I fear, however, that Stanley has not given (24) and (25) enough of a chance. The standard examples of implicit content generally only have the readings they do 
when placed in a suitable context, often a fairly rich one. Let us see what happens if we attempt to place (24) and (25) in a suitable context. (25), repeated here as (28), seems to me to respond particularly well to this treatment:

(John is a fantastically eminent and good-looking movie star. A speaker of an object-drop language with an imperfect command of English sees him greeting an adoring woman, leaving behind him a trail of further flustered and appreciative recipients of his salutations. Gesturing towards this group of women, he says the following.) *Everyone has had the privilege of having John greet.

In this context, it seems to me, we can perfectly well interpret (25) as having the meaning of (27), "Everyone has had the privilege of having John greet her," even though it is obviously not grammatical. Imagine further a scenario in which John, out jogging, stops and has animated and friendly conversations with several people along his route. Our non-native speaker of English could, I think, gesture towards this group and say (24) and be interpreted as meaning what would more naturally be expressed by (26).

The final part of Stanley's (2002a) critique is a generalization of the last one. Referring to the pragmatic enrichment approach, he says the following (Stanley 2002a: 164-165):

For if there were the sort of pragmatic processes postulated by the hypothesis, then there are countless examples of sentences that speakers should be able to use, without consciously and obviously flouting Gricean maxims, to communicate propositions that they in fact cannot thereby communicate.

Stanley gives one further example. If the pragmatic processes in question existed, he claims (2002a: 165), then speakers should be able to say (29) and communicate a content that would be expressed more fully by either (30a) or (30b).

(29) Everyone likes Sally.

(30) a. Everyone likes Sally and himself.

b. Everyone ${ }_{1}$ likes Sally and his ${ }_{1}$ mother.

I agree that (29) cannot be used with the content of (30a) or (30b). But I still see room for an advocate of the pragmatic enrichment approach to maneuver. A possible generalization that would rule out this case is the following:

\section{Generalization}

When the result of translating the sentence uttered into a language of thought string is fully propositional, it is not possible in pragmatic enrichment to add extra arguments to those contributed by items in the syntax. 
I do not know of any counterexamples to this generalization. Typically, implicit content, when it affects arguments of predicates at all, makes it clear who or what an argument present in the syntax actually refers to or ranges over, as when we understand everyone in (1) to be equivalent to everyone present at Neale's dinner party last night.

It might be objected that the principle just postulated on behalf of the pragmatic enrichment approach is rather ad hoc. This is a fair comment. But presumably the different varieties of the pragmatic enrichment approach would be able to bring their various pragmatic theories to bear in order to try to derive this principle from deeper and more general ones. Bach, for example, says that when the result of translating the sentence uttered into a language of thought string is fully propositional, enrichment is "needed if the speaker cannot plausibly be supposed to mean just what the sentence means" (Bach 1994: 139). One could strengthen that to "possible if and only if the speaker cannot plausibly be supposed to mean just what the sentence means" and then argue that every time one might plausibly be supposed to mean what (30a) or (30b) means one might also plausibly be supposed to mean what (29) means. I am not sure that this strategy in particular would work, although I do not see why it should not. But I think it is clear by now that Stanley has not produced a compelling argument against the pragmatic enrichment approach. At worst, he has forced the advocates of this approach to start thinking of ways to derive the plausible generalization in (31) from their pragmatic theories.

Overall, then, I do not think that Stanley and Szabó's argument from binding is very compelling.

\section{A New Argument from Binding}

In this section, I outline a new argument from binding. It shares certain characteristics with Stanley and Szabó's: in particular, it involves a sentence that lacks a bound reading that the pragmatic enrichment approach would appear to predict to be possible. But it also rules out certain other varieties of the local approach, including Stanley and Szabó's own.

As I have pointed out before in a slightly different context (Elbourne 2001b, 2005: 114), definite descriptions made with Saxon genitives (John's hat, Mary's cat) do not seem to be able to be bound. Let us consider (32) first, in order to be clear about the reading in question. (32) has the reading in (33), among others.

(32) John fed no cat of Mary's before it was bathed.

(33) There does not exist an individual $x$ such that $x$ is a cat of Mary's and John fed $x$ before $x$ was bathed.

In other words, no cat of Mary's can bind it here. A truth-conditionally identical reading is possible (for most speakers) when we substitute the definite description the cat of Mary's for it:

John fed no cat of Mary's before the cat of Mary's was bathed. 
There does not exist an individual $x$ such that $x$ is a cat of Mary's and John fed $x$ before the cat of Mary's identical to $x$ was bathed.

But when we put Mary's cat in the same place, the bound reading is not possible for any speakers:

John fed no cat of Mary's before Mary's cat was bathed.

(36) cannot have the reading in (35). We must see whether the theories we have been examining can explain this fact.

Let us begin with the pragmatic enrichment approach. If it were possible to add bound variables and other material freely in the language of thought, as this approach contends, we would surely be able to convert the representation of cat in Mary's cat from CAT to CAT IDENTICAL TO $x$, passing from the representation in (37) to the one in (38).

$$
\begin{aligned}
& \text { NO CAT OF MARY'S } x \ldots \text { MARY'S CAT WAS BATHED } \\
& \text { NO CAT OF MARY'S } x \ldots \text { MARY'S CAT IDENTICAL TO } x \text { WAS BATHED }
\end{aligned}
$$

Indeed, if the pragmatic enrichment approach is to be used to handle incomplete descriptions at all, its advocates will have to admit that CAT can be converted to CAT IDENTICAL TO $x$, or something similar, in the case of (34); otherwise they would not be able to analyze that example. But then they would seem to have no way to prevent the same transformation occurring, contrary to fact, in the case of (36). As mentioned above, the pragmatic enrichment approach cannot appeal to syntactic considerations to rule out readings that must be disallowed. And the unavailable reading of (36) does not involve new arguments being added to those provided in the overt syntax, as was the case in (29) and (30); it involves something for which there is a precise parallel in (34). I conclude that the pragmatic enrichment approach overgenerates.

Let us turn to the syntactic relation variable approach. Can the syntactic relation variable approach deal with the Saxon genitive data? It can, but only if it is supposed that the silent variables are attached to determiners, as proposed by von Fintel (1994) and others. Then we could suppose that, as a matter of idiosyncratic subcategorization properties, the can host one and Mary's cannot. The two cases would look like this, where $\mathrm{R}$ is a relation variable and pro is an individual variable:

$$
\text { [DP [the [R pro]] [NP cat of Mary's]] }
$$

$$
\text { [DP Mary's cat] }
$$

The syntactic relation variable approach can appeal to particular syntactic properties of the lexical items involved, unlike the pragmatic enrichment approach.

One might object at this point by pointing out that it is possible for definite descriptions built from Saxon genitives to be improper, as we see in (41). 
(41) (We are taking care of one of Mary's many cats. We return to see a vase knocked over.) Mary's cat must have done that.

It might seem that the syntactic relation variable approach must, ex hypothesi, admit that definite descriptions built from Saxon genitives can include a relation variable and an individual variable in order to deal with this. But if they did, they could surely be bound, contrary to what appears to be the case from (36).

There is an alternative analysis, however. Perhaps the definite determiner in Mary's cat already takes a relation variable and a lexical item of type e, but the item of type e is Mary. In other words, the syntactic structure pronounced Mary's cat would be a configuration like that in (42), where THE is a silent definite article:

\section{[DP [THE [R Mary]] [NP cat]]}

So there would be no room for a bindable individual variable. In the case of (41), $\mathrm{R}$ could mean something like "temporarily residing in this house and owned by." In other occurrences, $\mathrm{R}$ would take on other values, as suggested in work on the semantics of the genitive by Barker (1995) and others.

A corollary of this reasoning is that Stanley and Szabó must be incorrect when they say that their silent variables attach to NP in a structure [D NP]. Their position, like the pragmatic enrichment approach, is unable to distinguish between the cat of Mary's and Mary's cat. According to their theory, these phrases should be able to receive syntactic representations like these:

$$
\begin{aligned}
& \text { [DP the [NP [cat of Mary's] [R pro]]] } \\
& \text { [DP Mary's [NP cat [R pro]]] }
\end{aligned}
$$

These syntactic structures would of course result in both phrases being able to be bound.

Since this difficulty for their theory has arisen, we should examine the arguments in favor of placing the silent variables on NP that have been advanced by Stanley and Szabó. Two arguments are to be found in their writings. The first one (Stanley and Szabó 2000: 257) involves the sentence in (45), which they claim has the two readings in (46).

(45) Most people [GESTURE TOWARDS VILLAGE A] regularly scream. They are crazy.
a. "... The people in A are crazy."
b. "... The people in A who regularly scream are crazy."

Stanley and Szabó seem to assume that the definite description paraphrases in (46) mean that we are dealing with a descriptive or D-type pronoun (Sommers 1982, Neale 1990) and that, as is arguably necessary in such cases, the descriptive content of they is to be obtained from the descriptive content of constituents in the linguistic 
environment (Heim 1990, Neale 1990). They point out that if a pair of variables [R pro] is attached to most in (45), there is no constituent there that has as its value the set of people in the village. But if we have [people [R pro]], with pro referring to A and R meaning "living in," there is such a constituent. This would mean that the pronoun they could look back to this constituent and pick up its descriptive content from there, accounting for the reading in (46a).

The reading in (46b), Stanley and Szabó continue, can be derived on the basis of the first sentence of (45) from an independently motivated algorithm for dealing with D-type pronouns devised by Stephen Neale (1990):

If $x$ is a pronoun that is anaphoric on, but not c-commanded by, a nonmaximal quantifier ' $[D x: F x]$ ' that occurs in an antecedent clause ' $[D x$ : $F x](G x)$ ', then $x$ is interpreted as ' $[$ the $x: F x \& G x]$ '.

Applying this algorithm to the present case, and assuming that the variables are adjoined to people, we get the following as a possible translation for the pronoun in Neale's semi-formal language:

$$
\text { [the } x \text { : People-in-A }(x) \& \text { Regularly-Scream }(x) \text { ] }
$$

This does indeed represent the reading in (46b). So having the variables on the nominal, not on the determiner, easily accounts for both available readings. Having the variables on the determiner, Stanley and Szabó claim, would give no evident way to obtain these readings.

It is possible to counter this argument, however. Even if we accept that they in (45) must be a descriptive pronoun and that it must look to constituents of the previous sentence in order to obtain its descriptive content, we have not seen an argument that its descriptive content must be obtained only from there. In previous work, I have argued that descriptive pronouns are definite articles followed by Noun Phrases that have undergone phonological deletion (Elbourne 2001a, 2001b, 2005). If that is correct, then the word they in (45) could be a determiner followed by an unpronounced occurrence of people, elided on the basis of its occurrence in the previous sentence. The determiner they, moreover, could take a pair of a relation variable and an individual variable in the style of von Fintel (1994). So we would have the configuration in (49).

\section{[[they [R pro]] people]}

The variables [R pro] would be free to pick up salient values freely, as is normally the case, and would not be tied to assuming the values of constituents in the linguistic environment. So pro could refer to village A and R could mean either "who live in" or "who regularly scream and live in" as the case may be. Thus the two readings in (46) would be obtained. This combination of material that undergoes NP-deletion and salient content picked up more freely has proven to be independently useful in the analysis of donkey anaphora (Elbourne 2005: Chapter 4). 
Stanley and Szabó have a second argument to draw upon to show that their variables must be placed on Noun Phrases. Stanley (2002b) argues that definite descriptions involving nouns modified by superlative adjectives do not pick out the right things unless the LF variable is on the head noun. He proposes the scenario and example sentence in (50).

(50) (We are talking about Cornell students. The tallest person in the world is not a Cornell student.) The tallest person is nice.

This occurrence of the tallest person, in context, can easily pick out the tallest person among Cornell students. If the relevant variables are attached to person, Stanley points out, it is easy to see how this might come about: we have a complex [person [R pro]] that means "person who is a student at Cornell" and then tallest combines with it and yields the singleton set containing the tallest person in the set of Cornell students. But, Stanley says, if the variables had to appear on the they would do no good: person would denote the set of all people in the world and tallest would pick out the singleton set containing the tallest one of those; if the [R pro] complex places a requirement on this person that he be a Cornell student, contrary to fact, incoherence will result. So the variables had better go on person.

It appears, however, that Stanley is supposing that tallest operates as a unit: it picks out the tallest entity from among the set denoted by its nominal sister and gives us the singleton set containing this entity. But it has been proposed in the literature on superlatives that - est is a separate operator that takes as arguments a variable, the adjective and the noun (Heim 1999, Farkas and Kiss 2000, Herdan and Sharvit 2006). Two possible structures for this are given in (51), where a simple set variable $\mathrm{C}$ is used for simplicity instead of the combination [ $\mathrm{R}$ pro]; (51b), advocated by Heim (1999), obviously requires some covert movement to take place.
a. [tall [-est C]] person
b. [-est C] [tall person]

If one of these is the structure we are dealing with, then obviously Stanley's argument does not work. The noun person can still pick out the set of all the people in the world, but then restriction to the set of Cornell students comes in with the operator - est itself.

I conclude, then, that neither of Stanley and Szabó's arguments in favor of their placement of variables is valid, and that the data in (34) and (36) should make us prefer von Fintel's (1994) version of the syntactic relation variable approach.

Let us move on now to consider Neale's $(1990,2004)$ explicit approach. The explicit approach can arguably deal with the data in (34) and (36). This approach, recall, maintains that examples of the kind we have been looking at are short for longer English sentences that could have been uttered. The sentences in question have to be able to be constructed by adding lexical items to the material already present in the syntax. Suppose now that Mary's cat, by itself, does not contain any bindable individual variable. Neale (personal communication) points out that 
it does not seem to be possible to produce any syntactic extension of Mary's cat that would bring about binding. What modifiers can be added to Noun Phrases to produce anaphora? Precious few, and the ones that spring to mind (said, aforesaid, in question, relative clauses containing bound variables) are not grammatical when added to Mary's cat, as we see in (52). ${ }^{4}$
a. *Mary's said cat
b. *Mary's aforesaid cat
c. *Mary's cat in question
d. *Mary's cat that he was considering

By contrast, all of these modifiers can be grammatically added to the cat of Mary's:
a. the said cat of Mary's
b. the aforesaid cat of Mary's
c. the cat of Mary's in question
d. the cat of Mary's that he was considering

So Neale could assume that there is no bindable individual variable in the cat of Mary's either and account naturally for the contrast in (34) and (36). Alternatively, he could assume that the (but, crucially, not Mary's) regularly introduces a bindable individual variable as a matter of syntactic subcategorization (Elbourne 2001b, 2005; Neale 2004).

Let us now turn our attention to the syntactic situation variable approach. We are in a position to make an argument here analogous to the one made about the syntactic relation variable approach. Recall that the version of the syntactic situation variable approach currently advocated (Recanati 1996, 2004; Kratzer 2004) maintains that each predicate comes paired with a situation variable. It could possibly explain the bound reading of (34) by saying that the situation variable paired with cat (or cat of Mary's) in that sentence is bound. ${ }^{5}$ But then its advocates would seem to be forced to admit that there is nothing to stop the situation variable paired with cat in (36) being bound either, even though this would produce a bound reading of (36), contrary to fact.

This, of course, is a criticism precisely analogous to the one made of Stanley and Szabo's (2000) version of the syntactic relation variable approach, which put the variables on the Noun Phrases. It is worth exploring for a moment the consequences of making a move here analogous to the one I made in my discussion of Stanley and Szabo (2000). I maintained that the facts in (34) and (36) should

\footnotetext{
${ }^{4}$ The inability of definite descriptions constructed from Saxon genitives to take post-nominal modifiers, at least, was noted as far back as Chomsky 1986: 188.

${ }^{5}$ See Heim 1990, Percus 2000, Elbourne 2001a, 2005, and Büring 2004 for extensive discussion of binding situation variables.
} 
make us prefer the theory of von Fintel (1994), which placed the relation and individual variables on the determiners: the could host such a pair of variables, whereas Mary's could not. We should consider, then, the possibility of producing a variant of the syntactic situation variable approach that makes syntactic situation variables the arguments of determiners. Again, we could say that the hosts one and Mary's does not.

This will not do, however. Recall from example (41) that it is quite possible for Mary's cat and similar definite descriptions to be incomplete. The syntactic situation variables approach must maintain, ex hypothesi, that such uses crucially involve situation variables. But if we have a situation variable lurking somewhere in Mary's cat, and a system in place that allows binding of situation variables, we seem to predict incorrectly that Mary's cat will have a bound reading. The syntactic situation variable approach faces a real difficulty here, then.

Before we conclude, let us consider a possibly novel approach, which I will call the language of thought relation variable approach. According to this theory, there are no covert variables in the syntax to do the job of providing implicit content, contra von Fintel (1994) and Stanley and Szabó (2000). Lexical items in the syntax are translated into objects in the language of thought, as supposed by Sperber and Wilson (1986). Some of these language of thought objects are complexes that include variables that demand values to be assigned, as it were; at this level what this would presumably boil down to would be a requirement that certain language of thought objects be replaced by other, more contentful, ones. So a simplex lexical item the might be translated into a language of thought complex THE R PRO, where $\mathrm{R}$ PRO consists of a relation variable and an individual variable capable of being replaced by IDENTICAL-TO $x$. But Mary's and other Saxon genitives, as a matter of their idiosyncratic meaning, would not be translated into language of thought objects of this kind. In other words, we take von Fintel's (1994) theory and transpose it into the language of thought. I cannot see any disadvantages to this theory at the moment.

\section{Conclusion}

We started our investigation with the following theories on the table: the syntactic relation variable approach in two versions (those of von Fintel 1994 and Stanley and Szabó 2000), the pragmatic enrichment approach, the explicit approach, and the syntactic situation variable approach. Add to these the late-arriving language of thought relation variable approach just described. Examination of the binding possibilities of Saxon genitives has proven to be quite informative. In particular, the only theories that can deal straightforwardly with Mary's cat seem to be the syntactic relation variable approach in von Fintel's version, the explicit approach, and the language of thought relation variable approach. It will be interesting to see if future work can distinguish between these latter theories. 


\section{References}

Bach, Kent: 1994, 'Conversational impliciture', Mind \& Language 9, 124-162.

Bach, Kent: 2005, 'Context ex machina', in Z. Szabó (ed.) Semantics versus Pragmatics, Oxford University Press, Oxford.

Barker, Chris: 1995, Possessive Descriptions, CSLI Publications, Stanford, CA.

Büring, Daniel: 2004, 'Crossover situations', Natural Language Semantics 12, 23 62.

Carston, Robyn: 1988, 'Implicature, explicature, and truth-theoretic semantics', in R. Kempson (ed.) Mental Representations: the Interface between Language and Reality, Cambridge University Press, Cambridge.

Carston, Robyn: 2002, Thoughts and Utterances, Blackwell, Oxford.

Chomsky, Noam: 1986, Knowledge of Language. Its Nature, Origin and Use, Praeger, Westport, Conn.

Elbourne, Paul: 2001a, 'E-type anaphora as NP-deletion', Natural Language Semantics 9, 241-288.

Elbourne, Paul: 2001b, 'On the semantics of pronouns and definite articles', in L. Bar-el and K. Megerdoomian (eds.) WCCFL 20: Proceedings of the 20th West Coast Conference on Formal Linguistics, Cascadilla Press, Somerville, MA.

Elbourne, Paul: 2005, Situations and Individuals, MIT Press, Cambridge, MA.

Farkas, Donka and Katalin Kiss: 2000, 'On the comparative and absolute readings of superlatives', Natural Language and Linguistic Theory 18, 417-455.

von Fintel, Kai: 1994, Restrictions on Quantifier Domains. Doctoral Dissertation, University of Massachusetts, Amherst.

Fodor, Jerry: 1975, The Language of Thought, Harvard University Press, Cambridge, MA.

Heim, Irene: 1990, 'E-type pronouns and donkey anaphora', Linguistics and Philosophy 13, 137-177.

Heim, Irene: 1999, 'Notes on superlatives', ms., MIT.

Heim, Irene and Angelika Kratzer: 1998, Semantics in Generative Grammar, Blackwell, Oxford.

Herdan, Simona and Yael Sharvit: 2006, 'Definite and nondefinite superlatives and NPI licensing', Syntax 9, 1-31.

Kratzer, Angelika: 2004, 'Covert quantifier restrictions in natural languages', ms., University of Massachusetts, Amherst.

Kuroda, Sige-Yuki: 1982, 'Indexed predicate calculus', Journal of Semantics 1, 43-59. 
Martí, Luisa: 2003, Contextual Variables. Doctoral Dissertation, University of Connecticut.

Martí, Luisa: 2006, 'Unarticulated constituents revisited', Linguistics and Philosophy 29, 135-166.

Neale, Stephen: 1990, Descriptions. MIT Press, Cambridge, MA.

Neale, Stephen: 2004, 'This, that and the other', in M. Reimer and A. Bezuidenhout (eds.) Descriptions and Beyond, Clarendon Press, Oxford.

Neale, Stephen: 2007, 'On location', in M. O'Rourke and C. Washington (eds.) Situating Semantics: Essays on the Philosophy of John Perry, MIT Press, Cambridge, MA.

Percus, Orin: 2000, 'Constraints on some other variables in syntax', Natural Language Semantics 8, 173-229.

Perry, John: 1986, ‘Thought without representation', Supplementary Proceedings of the Aristotelian Society 60, 263-283.

Recanati, François: 1993, Direct Reference. From Language to Thought, Blackwell, Oxford.

Recanati, François: 1996, 'Domains of discourse', Linguistics and Philosophy 19, 445-475.

Recanati, François: 2002, 'Unarticulated constituents', Linguistics and Philosophy 25, 299-345.

Recanati, François: 2004, Literal Meaning, Cambridge University Press, Cambridge.

Recanati, François: 2007, 'It is raining (somewhere)', Linguistics and Philosophy 30, 123-146.

Soames, Scott: 1986, 'Incomplete definite descriptions', Notre Dame Journal of Formal Logic 27, 349-375.

Sommers, Fred: 1982, The Logic of Natural Language, Clarendon Press, Oxford.

Sperber, Dan and Deirdre Wilson: 1986, Relevance: Communication and Cognition, Blackwell, Oxford.

Stanley, Jason: 2000, 'Context and Logical Form', Linguistics and Philosophy 23, 391-434.

Stanley, Jason: 2002a, 'Making it articulated', Mind \& Language 17, 149-168.

Stanley, Jason: 2002b, 'Nominal restriction', in G. Preyer and G. Peter (eds.) Logical Form and Language, Clarendon Press, Oxford.

Stanley, Jason and Zoltán Szabó: 2000, 'On quantifier domain restriction', Mind \& Language 15, 219-61.

Westerståhl, Dag: 1985, 'Determiners and context sets', in J. van Benthem and A. ter Meulen (eds.) Generalized Quantifiers in Natural Language, Foris, Dordrecht. 